\title{
THE RELATIONSHIP OF AGILITY AND BALANCE TESTS RESULTS OF YOUNG FEMALE SKATERS WITH COMPETITION SCORES IN FIGURE SKATING
}

\author{
A. IONESCU ${ }^{1}$ V. IONESCU ${ }^{2}$
}

\begin{abstract}
The study aimed to highlight the relation between the performance registered by female skaters in agility and balance tests with their competition scores. Within our research, we applied three standardised tests designed to assess the athletic abilities that support on-ice skills development from Standardised Testing of Athleticism to Recognise Skaters (S.T.A.R.S.), consisting of one agility test (the Hexagon Test) and two balance tests (the Stork Test with eyes open and with closed eyes). The research was conducted on a group of 30 female skaters from Romania and Turkey during August-September 2019, with the age range from 10 to 12 years ( $x=10.87$, $S D=0.73)$. The study showed that there is a significant correlation between the agility test $(p=0.046)$ and the balance test with opened eyes $(p=0.043)$. Still, there was no significant relevance between the closed eyes balance test $(p=0.192)$ and the scores earned in competitions by skaters. The results of the study aimed to guide coaches in choosing the proper tests for evaluating their skater's performance.
\end{abstract}

Key words: figure skating, agility, balance, off-ice performance.

\section{Introduction}

Figure skating has the benefit of being one of the few sports disciplines in which the athlete's performance is evaluated on both their physical abilities and their artistic expressions. Since its first manifestation on frozen lakes [7] till the present times, the sport has evolved in three distinct disciplines: singles (male/female), pairs and ice dancing [23]. Although all fields have common grounds, some aspects differentiate them from each other. While singles and pairs competition routines include jumps, spins, steps and lifts (pairs) in a choreographed complex, the distinction in ice dancer's performance is the absence of jumps.

Under the pressure of being subjective [6], the judging system in figure skating

\footnotetext{
${ }^{1}$ Department of Motric Performance, Faculty Transilvania University of Brasov, Romania

${ }^{2}$ Interdisciplinary Doctoral School, Transilvania University of Brasov, Romania
} 
has evolved throughout the years into a more complex and objective system that has clear rules for evaluating performance. Within the current ISU judging system, a routine is divided into two parts; technical score and presentation score [10]

Thus, both components are equally crucial in the competitions' overall score; the objective part remains the technical score, including jumps, spin, and step sequences. [28]

This supports the prevalence of scientific research that focused on technical elements that further stimulated a significant advancement in technical components.

Therefore there has been a longstanding interest in the biomechanics of figure skating jumps and the cinematic characteristics of multi revolution jumps.[11],[12]. Further studies have focused on the implication for the training of performing triple and quadruple jumps [13] by emphasising the biomechanical conditions that have an impact on strength and conditioning programmes.

McMaster et al. [18] is one of the first who tested the workability of adapting classical interval training methods to the specific demands of figure skating. The study has shown evidence for a low level of maximum oxygen consumption for skaters who trained an average of 5 hours per week as well as an improvement in speed on average by $10 \mathrm{sec}$ in a $1 / 2$ mile skate test coupled with a decrease in maximum heart rate and also greater control of difficult jumps during the program. Besides, it supported the fact that improved strength and endurance may minimise the occurrence of stressrelated injuries.

While some studies [14], [18]focused on the benefits of strength and conditioning programmes applied for off-ice training, other studies have pointed indirect support of the importance of implementing balance and postural control [25] exercises in preventing the common injuries that figure skaters can experience [8], [15].

It is widely assumed that several factors concur in assessing a figure skater performance, including muscle strength [9], [21], flexibility [18], balance [21], [25], agility[26] and also the capacity to express and transmit the emotions trough choreographic movements [19].

Overall, the previous studies have approached various questions that provided a scientific insight into the specific problems that the discipline of figure skating has and ways to increase performance. However, it remains an open question of whether there is a significant relationship between the test that are designed to evaluate off-ice performance and competition scores. The United States Skating Association has developed an off-ice fitness assessment composed of 15 off-ice tests that evaluate skaters in four main directions: agility, balance and coordination; strength and power; and flexibility [29].

According to the National Strength and Conditioning Association agility is the ability of an athlete to move his whole body in multiple directions with multiple changes in velocity as quickly as possible without affecting the effectiveness of the movement [24]. In figure skating a good agility translates into the capacity to "change directions and positions while maintaining balance and coordination". Likewise balance is defined as: "the ability to keep steady with an equal amount of weight on each side of the body."[1] 
The goal of the present article is to highlight the relation between the performance registered by female skaters in agility and balance tests with their competition scores.

We hypothesise that good scores in balance and agility tests predict better performance in competitions. For this purpose, we applied three standardised tests designed to assess the athletic abilities that support on-ice skills development from Standardised Testing of Athleticism to Recognise Skaters (S.T.A.R.S.) Programme. The set of tests included one agility test (the Hexagon Test) and two balance tests (the Stork Test with eyes open and with closed eyes). Subsequently, we registered the competition scores and analysed them to test our hypothesis.

\section{Objectives (The Hypotheses and the Purpose of the Research)}

The increased technical difficulty of the program components that have been observed in the past years has raised many questions regarding the number of training hours young skaters should attend. Furthermore, there has been a degree of concern regarding the young age of the competitors and the impact that overtraining has on their development [2].

There are several ways to estimate the effectiveness of the on-ice training programme by analysing the competition score (total segment score). The total segment score is divided into total element score and total program component score. The total element score for jumps, spins and steps is comprised by the scores earned for each executed element (base value) multiplied with the judge's appreciation of the grade of execution of the elements. In addition, the program components score (presentation score) encompasses five components (skating skills, transitions, performance, compositions and interpretation of the music)for which judges have to award points from 0.25 to 10.00 to grade the overall presentation of the routine.

On the grounds that every element is evaluated based on the grade of execution and also the choreography of the program is devised in five different components, coaches can quickly determine, by analysing the judge's score, which part of the on-ice training programme can be ameliorated.

Some specialists in the domain along with King [12], suggested that in order to maintain the current level of performance that is required for elite skaters, athletes should improve their physical capabilities such as strength, flexibility and power.

It is important to note that there is no clear delimitation in the judge's scores that can assess the level of physical capacities enlisted above. Although the importance of off-ice training programmes are clearly defined by numerous studies [3], [4], [16], [18], [21], [26]]. Most of the studies include measurements tools that either require a specialist or are inaccessible outside a laboratory.

The research questions that have arisen from this particular problem are: How can coaches evaluate the effectiveness of the off-ice training programme based on competition scores and if the selected tests that evaluate agility and balance have significant importance regarding the competition scores gained by the skaters.

Our study starts from the premise that the evaluation methods must be accessible to all coaches regardless of the 
level of expertise or the club's budget designated for research equipment.

The purpose of this study is to identify if there is any relationship between the results registered in specific parameters of the figure skating off ice abilities and the scores of the overall competition.

More precisely, we predict that good scores in agility and balance test have a positive influence on the total technical elements score.

One of the objectives of the research was to provide coaches and athletes with a shred of scientific evidence in choosing the relevant tests for assessing off-ice abilities that have an impact on the skater's competition performance.

Another objective was to determine if evaluation methods that are accessible to coaches can be used as reliable predictors for on-ice performance.

\section{Materials and Methods}

\subsection{Participants}

The study sample included 30 female figure skaters. This cross-sectional study included skaters from three figure skating clubs, two from Ankara, Turkey and one from Brasov, Romania. To meet the inclusion criteria, skaters had to be active and healthy with good attendance (80\%) at practice. The exclusion criteria: less than $80 \%$ attendance of the daily practices. Age sample characteristics: $10,86 \pm .13$. Average height: $132,76 \pm 1,72$. The average weight of the skaters: $29,39 \pm$ 1,01. All athletes are competitive skaters, participating in national and international competitions at Cubs and Novice categories. The study was carried out in accordance with the guidelines contained in the declaration of Helsinki, and informed written consent was obtained from all subjects and their legal guardians.

\subsection{Study design}

The study used a transverse design that encompassed three tests that are aimed to measure agility and balance levels of the skaters. The tests were selected from S.T.A.R.S. Programme, set of tests. Moreover, the results registered were compared with the other skater's performance using the 2016 S.T.A.R.S. Raw scores results feedback worksheet [30] and also with the total element score gained by athletes in national competitions that succeeded, consisting in the dependent variable.

\subsection{Materials}

Two balance tests were chosen, the Stork test with opened eyes and with closed eyes, which were executed only on the dominant foot (left foot, for all subjects that rotate in the air in counterclockwise direction).

From the agility tests set, we preferred the Hexagon test that measures the reaction time while jumping in and out around each of the sides of a marked hexagon in clockwise direction for a total of 18 two-footed vertical jumps. Unlike the T-test the Hexagon test requires a smaller testing area, therefore is more suitable for testing in an enclosed space such as an ice rink surroundings.

The materials that were used for conducting the research were: ruler, stop watch and tape.

The hexagon shape had all angles at $120^{\circ}$ and all sides were measured to correspond to $61 \mathrm{~cm}$. 


\subsection{Procedure}

The experiment consists of two phases. In the first phase we measured the height, weight and age of the athletes and subsequently we registered the performance in each of the selected tests. The second phase consisted in analysing and registering the competition scores.

The athleticism tests took place during two summer training camps in Tukey and in Romania in August- September 2019. The order of the tests was established in accordance with the "Principles of test selection and administration" [5].The tests were scheduled before the ice practice and after a through warm-up.

First the skaters were showed the correct position of the Stork test and encouraged to practice the position for several seconds, prior to the actual test and also, they were allowed to practice a performance of the hexagon test at sub maximal speed to accustom with the procedure.

Two evaluators were set for each of the tests in order to minimise the measurement errors in timing each performance.

First the participants had to complete the balance tests and finally the agility test. All participants had 2-3 min breaks between the tests.

For both balance tests (Stork test with eyes opened and with closed eyes) the evaluators were instructed to stop timing the performance if the athlete would imbalance and change in any way the requested position, additionally for the test without visual stimulus timing was stopped when the athlete opened the eyes. In order to facilitate the observation of any rebalance made by the skater on the standing leg, a taped marked position was set. Athletes were instructed prior to execution that a longer period means a greater balance.

The Hexagon Agility test begins with the athlete standing on a centred marked position, on an auditory signal given by one of the evaluators, the skater starts performing two legged jumps on each side of the hexagon, returning each time in the centre, for two continuous clockwise turns. The athletes were instructed that a shorter time of execution means greater agility. The evaluators were advised to stop the test if one of the following events occurred:

- athlete fails to jump outside the hexagon or lands on the tape,

- athlete changes direction or misses a side of the hexagon,

- athlete falls, steps out or takes extra steps.

If one of the above-mentioned events occurred the skater was allowed another trial after a resting period.

\subsection{Statistical analysis}

All the recorded data was processed with IBM SPSS Statistics version 26. The statistical analysis included the arithmetic average $(X)$, standard deviation (SD), normality test, Pearson's ( $r$ ), one sample T-Test.

Descriptive statistics were used to determine means and standard deviations of physiological variables. The Pearson's ( $r$ ) correlation determined the individual strength of relationships between the independent (off-ice) and dependent variables (on-ice).

An alpha level of $p<0.05$ was used in all analyses. 


\section{Results}

Before we analysed the data we assessed if the off ice tests mean values correspond with the mean values provided in the 2016 S.T.A.R.S. RAW Scores Results Feedback Worksheet using one sample T-Test. By comparing the means of the same age group and same sex for the Hexagon Test, the Stork test and the closed eyes Stork test. Mean Hexagon Test time $(M=13.70, S D=0.47)$ was similar with population 'normal' time of $13.6 \mathrm{sec} . \quad(M=13.6),. \mathrm{t}(29)=0.22$, $\mathrm{p}=0.827$

\begin{tabular}{|c|c|c|c|c|c|c|}
\hline & & & & Value $=13.6$ & & \\
\hline & & & Sig. (2- & Mean & $\begin{array}{l}95 \% \text { Confid } \\
\text { of the D }\end{array}$ & $\begin{array}{l}\text { e Interval } \\
\text { rence }\end{array}$ \\
\hline & $\mathrm{t}$ & df & tailed) & Difference & Lower & Upper \\
\hline Hexagon Test (sec.) & .220 & 29 & .827 & .10433 & -.8651 & 1.0738 \\
\hline
\end{tabular}

The results showed in Table 1 suggest that there is no significant difference between the results registered by the subjects and the mean results reported in 2016 S.T.R.A.S. RAW Scores Results Feedback Worksheet. Table 2 results reveal a significant difference for Stork test time $(M=79.36, S D=38.65)$ registered by the subject and 'normal' time of $M=94.99$, $\mathrm{t}(29)=-2.213, \mathrm{p}=0.035$ reported in 2016 S.T.R.A.S. RAW Scores Results Feedback Worksheet

Test Value $=94.99$

\begin{tabular}{cc|c|c|c|c|c} 
& & & & \multicolumn{2}{c|}{} & \multicolumn{2}{c}{$\begin{array}{c}\text { 95\% Confidence Interval of } \\
\text { the Difference }\end{array}$} \\
& $\mathrm{t}$ & $\mathrm{df}$ & $\begin{array}{c}\text { Sig. (2- } \\
\text { tailed) }\end{array}$ & $\begin{array}{c}\text { Mean } \\
\text { Difference }\end{array}$ & Lower & Upper \\
\hline Stork Test (sec.) & -2.213 & 29 & .035 & -15.62133 & -30.0554 & -1.1872 \\
\hline
\end{tabular}

One-Sample Test for closed eyes Stork Test

Table 3

\begin{tabular}{ll|l|r|r|r|r} 
& & & \multicolumn{4}{c}{ Test Value = 13.99 } \\
& & & Sig. (2- & Mean & \multicolumn{2}{c}{$\begin{array}{c}\text { 95\% Confidence Interval } \\
\text { of the Difference }\end{array}$} \\
& $\mathrm{t}$ & $\mathrm{df}$ & tailed) & Difference & Lower & Upper \\
\hline Blind Stork Test (sec.) & .569 & 29 & .574 & .87033 & -2.2594 & 4.0000 \\
\hline
\end{tabular}


There was no significant difference between the results of the closed eyes Stork test $(M=14.86, S D=8.38)$ and the results reported in 2016 S.T.R.A.S. RAW
Scores Results Feedback Worksheet $M=13.99, \mathrm{t}(29)=0.569, \mathrm{p}=0.574$ as showed in Table 3.

\begin{tabular}{|c|c|c|c|c|c|}
\hline & & $\begin{array}{l}\text { Hexagon } \\
\text { Test (sec.) }\end{array}$ & $\begin{array}{l}\text { Stork Test } \\
\text { (sec.) }\end{array}$ & $\begin{array}{c}\text { Closed eyes } \\
\text { Stork Test } \\
\text { (sec.) }\end{array}$ & $\begin{array}{l}\text { Total } \\
\text { Element } \\
\text { Score } \\
\text { (points) }\end{array}$ \\
\hline \multirow[t]{3}{*}{ Hexagon Test (sec.) } & $\begin{array}{l}\text { Pearson } \\
\text { Correlation }\end{array}$ & 1 & $-.373^{*}$ & $-.427^{*}$ & $-.367^{*}$ \\
\hline & Sig. (2-tailed) & & .042 & .019 & .046 \\
\hline & $\mathrm{N}$ & 30 & 30 & 30 & 30 \\
\hline \multirow[t]{3}{*}{ Stork Test (sec.) } & $\begin{array}{l}\text { Pearson } \\
\text { Correlation }\end{array}$ & $-.373^{*}$ & 1 & $.373^{*}$ & $.371^{*}$ \\
\hline & Sig. (2-tailed) & .042 & & .042 & .043 \\
\hline & $\mathrm{N}$ & 30 & 30 & 30 & 30 \\
\hline \multirow[t]{3}{*}{$\begin{array}{l}\text { Closed eyes Stork } \\
\text { Test (sec.) }\end{array}$} & $\begin{array}{l}\text { Pearson } \\
\text { Correlation }\end{array}$ & $-.427^{*}$ & $.373^{*}$ & 1 & .245 \\
\hline & Sig. (2-tailed) & .019 & .042 & & .192 \\
\hline & $\mathrm{N}$ & 30 & 30 & 30 & 30 \\
\hline \multirow[t]{3}{*}{$\begin{array}{l}\text { Total Element Score } \\
\text { (points) }\end{array}$} & $\begin{array}{l}\text { Pearson } \\
\text { Correlation }\end{array}$ & $-.367^{*}$ & $.371^{*}$ & .245 & 1 \\
\hline & Sig. (2-tailed) & .046 & .043 & 192 & \\
\hline & $\mathrm{N}$ & 30 & 30 & 30 & 30 \\
\hline
\end{tabular}

*. Correlation is significant at the 0.05 level (2-tailed).

A Pearson product-moment correlation coefficient was computed to identify the relationship between the scores of the off-ice tests and the Total segment score (on-ice test) as showed in Table 4 above.

There was a negative correlation between the Hexagon Test scores and Total Element scores, $r=-0.367, \mathrm{n}=30$, $p=0.046$, a positive correlation between Stork Test and Total Element score, $r=$ $0.371, n=30, p=0.046$.

Furthermore, there was no significant correlation between closed eyes Stork Test scores and Total Element Scores where $r=0.245, n=30 p=0.192$.
Overall, there was a positive correlation between Hexagon test scores and Stork test scores and higher Element scores in competition.

A decrease in registered time of the Hexagon test was correlated with an increase of total element score and an increase in registered time of Stork test was correlated with increases in total element score.

\section{Discussions and Conclusions}

In the present article, we investigated whether the scores of agility and balance 
test are correlated with the technical scores from competitions. In line with our hypothesis, our results showed that two out of three tests are correlated with the total element scores.

Our findings converged with previous findings [16], [17], [18], [27]. In addition, they show for the first time that the tests used for evaluation of off-ice abilities may not have any relationship with the competitive scores earned by skaters.

The results of our study offer a novel perspective on the importance of choosing relevant and accessible off-ice testing for coaches. The most important limitation is that the study sample included only female skaters. Another limitation is that the sample skaters were in the same age category and level of skating. Although the subjects that participated in this study are only female skaters of the same age and skating level, we observed that for two of the off-ice test there was no significant difference between our sample size and the general population observed in the 2016 S.T.R.A.S. RAW Scores Results Feedback Worksheet [30].

Future research may extend this work by analysing more physical parameters that are involved in figure skating performance, such as the neuromuscular and physiological response of the organism to specific efforts [22] and the effect of different types of specific effort on respiratory volumes [20]. We consider that the above-mentioned studies can provide further insight in assessing and adapting the training programme.

\section{References}

1. Balance definition. Available at https://www.oxfordlearnersdictionari es.com/definition/english/balance_1.

Accessed: 09.10.2021

2. Birrer, D., Lienhard, D., Williams, et al.: Prevalence of non-functional overreaching and the overtraining syndrome in Swiss elite athletes. In: Schweizerische Zeitschrift Fur Sportmedizin Und Sporttraumatologie, 61(4), 23-29. 10.24451/arbor.11079

3. Brown, T. D., Vescovi, J. D.: Efficient Arms for Efficient Agility. In: Strength and Conditioning Journal, 2003, 25(4), p. 7-11.

4. Cummins, L. F.: Figure skating: A different kind of youth sport. In: Journal of Clinical Sport Psychology, 1(4), 390-401. https://doi.org/ 10.1123/jcsp.1.4.390

5. McGuigan, M.: Principles of test selection and administration. In: Essentials of Strength Training and Conditioning, 4th ed.; Haff, GG, Triplett, NT, Eds. 2016: p.249-258.

6. Findlay, L.C., Ste-Marie, D.M.: $A$ Reputation Bias in Figure Skating Judging. In: Journal of Sport and Exercise Psychology, 26(1), p.154-166. https://doi.org/10.1123/jsep.26.1.154

7. Formenti, F., Minetti, A.E.: The first humans travelling on ice. In: Biological Journal of the Linnean Society; 93(1), 2008, p. 1-7.

8. Fortin, J. D., Roberts, D.: Competitive Figure Skating Injuries an Original Contribution. In: Pain Physician, 66(3), 2003, p.313-318.

9. Fortin, J., Harrington, L.S., Langenbeck, D.F.: The Biomechanics of Figure Skating. In: Physical Medicine and Rehabilitation, 11(3), 1997, p.627-648.

10. Handbooks Single \& Pair Skating., Available at : 
https://www.isu.org/figureskating/rules/fsk-judging-system Accessed : 27.09.2020

11. King, D.: A biomechanical analysis of the Axel: critical parameters for successful jumps. In: Professional Skater, 28(1), 1997, p.10-12. https://doi.org/10.1139/h05-153

12. King, D.L.: Performing triple and quadruple figure skating jumps: implications for training. In: Canadian Journal of Applied Physiology = Revue Canadienne de Physiologie Appliquee, 30(6), 2005, p.743-753. https://doi.org/10.1139/h05-153

13. King, D., Smith, S., Higginson, B., et al.: Figure Skating: Characteristics of triple and quadruple toe-loops performed during the Salt Lake City 2002 winter olympics. In: Sports Biomechanics, 3(1), 2004 p. 109-123. https://doi.org/10.1080/14763140408 522833

14. Kovacs, E.J., Birmingham, T.B., Forwell, L., et al.: Effect of Training on Postural Control in Figure Skaters. In: Clinical Journal of Sport Medicine, 14(4), 2004, p.215-224. https://doi.org/ 10.107/00042752-200407000-00004

15. Lipetz, J., Kruse, R. J.: Injuries and Special Concerns of Female Figure Skaters. In: Clinics in Sports Medicine, 19(2), 2000, p. 369-380.

16. Poe, C., O'Bryant, H., Donald, E.: Off Ice Resistance and Plyometric Training for singles figure skaters. In: Strength and Conditioning Journal, 16(3), 1994, p.68-76.

17. Mannix, E. T., Healy, A., \& Farber, M. O.: Aerobic power and supramaximal endurance of competitive figure skaters. In: The Journal of Sports Medicine and Physical Fitness, 36(3), 1996, p.161-168.
18. McMaster, W. C., Liddle, S., Walsh, J.: Conditioning program for competitive figure skating. In: The American Journal of Sports Medicine, 7(1), 1979, p.43-47.

https://doi.org/10.1177/03635465790 0700110

19. Moormrnn, P. P.: Choreography styles in figure skating. In: Journal of Creative Behavior, 40(4), 2006, p.265287. https://doi.org/10.1002/j.21626057.2006.tb01277.x

20. Olaru, M., Bîcă, M., Plăstoiu, C., et al.: Effort's influence on respiratory volumes and flows. In: Rehabilitation Management. Romanian Journal of Physical Therapy, 18(30), 2012, p.71.

21. Podolsky, A., Kaufman, K. R., Calahan, T. D., et al.: The relationship of strength and jump height in figure skaters. In: The American Journal of Sports Medicine, 18(4), 1990, p. 400-405.

22. Puiu, M., Dragomir, A.: Neuromuscular and physiological assessment during a vertical jumping test in aerobic gymnastics. In: BRAIN. Broad Research in Artificial Intelligence and Neuroscience, 11(4Sup1), 2021, p.156-166.

23. Rand, E.: Figure Skating in the Formative Years: Singles, Pairs, and the Expanding Role of Women. In: International Journal of the History of Sport, 32(11/12), 2015, p.1528-1530.

24. Sands, W.A., Wurth, J. J., Hewit, J. K.: Basics of Strength and Conditioning Manual. In: The National Strength and Conditioning Association (Vol. 207). 2012. at: http://www.ncbi.nlm.nih. gov/pubmed/23447811 Accessed: 10.09.2021

25. Saunders, N.W., Hanson, N.J., Koutakis, P.: Figure skater level moderates balance training. In: 
International Journal of Sports Medicine, 34(4), 2013, p.345-349. https://doi.org/10.1055/s-00321327653

26. Slater, L. V., Vriner, M., Zapalo, P., et al.: Difference in Agility, Strength, and Flexibility in Competitive Figure Skaters Based on Level of Expertise and Skating Discipline. In: Journal of Strength and Conditioning Research, 30(12), 2016, p. 3321-3328. https://doi.org/10.1519/JSC.00000000 00001452

27. Smith, A. D.: The young skater. In: Clinics in Sports Medicine, 19(4), 2000, p. 741-755. https://doi.org/ 10.1016/S0278-5919(05)70235-0

28. SPECIAL REGULATIONS \& TECHNICAL RULES. 2018.

at

https://www.isu.org/figure-

skating/rules/fsk-regulations-

rules/file. Accessed: 15.09.2021

29. https://www.usfigureskating.org/skat e/prepare-and-train/athleticassessments. Accessed 18.07.2019

30. http://www.usfsa.org/content/Raw_D ata_Worksheet.pdf Accessed 8.09.2018 